\title{
Study on Carbon Emissions from Municipal Solid Waste in Shenzhen
}

\author{
Junfeng Zhang ${ }^{1, \text { a }}$, Hong Fang ${ }^{2, b}$, Bofei $\mathrm{Ma}^{3, \mathrm{c}}$ and Huaimo You ${ }^{4, \mathrm{~d}}$ \\ ${ }^{1}$ School of Economics and Management, Beihang University, 37 Xueyuan Road, Beijing 100191, \\ China \\ ${ }^{2}$ School of Economics and Management, Beihang University, 37 Xueyuan Road, Beijing 100191, \\ China \\ ${ }^{3}$ School of Economics and Management, Beihang University, 37 Xueyuan Road, Beijing 100191, \\ China \\ ${ }^{4}$ School of Economics and Management, Beihang University, 37 Xueyuan Road, Beijing 100191, \\ China \\ azhangjunfeng136@163.com, bHongfan0097@sina.com, 'cmabofei@buaa.edu.cn., \\ dyouhuaimo@foxmail.com
}

Keywords: Municipal solid waste (MSW), Landfill, Incineration, Composting, Carbon emission Abstract. There are generating many municipal solid wastes in the rapid development of urbanization. Municipal solid wastes treatment could generate lots of carbon emissions, which accounted for an important share in total carbon emissions. Therefore, it is crucial to compare emissions from different ways of municipal solid wastes treatment and find the most effective one. This paper calculates municipal solid wastes treatment through landfill, incineration, and composting from 2000 to 2010 in Shenzhen city. The results demonstrate landfill produce more carbon emissions than composting and incineration. So, we should popularize composting, garbage classification and promoting power generation during the process of waste incineration in order to reduce carbon emission during refuse disposal.

\section{Introduction}

Accompanying the fast development of economy and the promoting of the urbanization rate in China, the problems of urban environment gradually stood out. Waste treatment was related closely to the daily life of the inhabitants, which has already become an important issue urgently to be solved. China has been striving to explore effective channels to handle the problems of municipal solid waste treatment for a long time. Compared with the developed countries, we must concede that China still lags far behind in this regard and the future situation will be not so optimistic. According to incomplete statistics, most of cities were already surrounded by waste and some of cities had no available place for landfills in 600 various Chinese cities. The majority of cities suffer from several issues, such as rampant rubbish storage, low rubbish utilization, under-developed methods, environmental disruption, etc.

The contaminant produced by litter decomposition was different because of the different process modes. Landfill, incineration and compost were three modes for municipal waste treatment, which produced carbon emission during the process. According to statistics, there were more than 1 billion tons of MSW in the whole world each year and about $92 \%$ of them were processed by landfill, the $60 \%$ to $70 \%$ among which were simple landfill. Incineration and compost mainly used in the some developed countries. According to the statistical data in 2009, the three modes processed 56.6\%, $12.9 \%$ and $1.9 \%$ solid waste respectively in China. The remaining wastes were disposed by stacking and landfill simply.

In order to formulate target-oriented policies and measures to reduce MSW carbon emissions, domestic and foreign scholars have done lots of studies on carbon emissions rules of different processing modes, such as landfill, incineration, composting [1]. Life Cycle Assessment(LCA), Intergovernmental Panel on Climate Change(IPCC) recommendatory methods, as well as Clean Development Mechanism(CDM) based calculation method have been adopted to analyze 
carbon emissions of municipal solid wastes treatment techniques and the whole processing system[2]. Using it as a base, numerous feasible and effective plans have been proposed, which included advanced technology, appropriate classification system [3], optimized the process [4], etc. Chen et al (2007) adopted the empirical formulae that recommended in IPCC 1996 Guideline to estimate the amount of greenhouse gases that generated by landfill gas (LFG) in China every year [5]. They proposed landfill gas (LFG) would display awesome recycling potential. Some researchers adopted empirical formulae that recommended in IPCC 1996 Guideline and Life Cycle Assessment (LCA) respectively, through which to calculate and compare carbon emissions generated by three different approaches that used to process municipal solid waste. They found that the IPCC 1996 Guideline could provide a lot of defaults, which would be more suitable to estimate the amount of carbon emissions generated during municipal solid waste process.

However, although many scholars have researched the carbon emission of municipal solid wastes by many methods, no scholars compared with the carbon emission of municipal solid wastes by landfill, incineration and composition in one city. So, in this paper, we take Shenzhen as an example to analyze the composition of household waste and calculate the amount of carbon emissions created by landfill, incineration and composting as well as its dynamic transformation trend. Thus, we elicit optimal municipal solid wastes treatment method to provide data support and decision-making basis for optimized management of municipal waste.

The structure of the paper is arranged as follows: In Section 2, we show the calculation of carbon emission of MSW. Section 3 presents the results and discussion. Section 4 presents conclusion.

\section{The calculation of carbon emissions of MSW}

This paper will illustrate the carbon emission calculation of different disposal methods.

The calculating carbon emission of waste landfill is as following:

\section{$\mathrm{ECO}_{2}=\mathrm{W} * \mathrm{DOC}^{*} \mathrm{DOC}_{\mathrm{F}} *(1-\mathrm{MCF} * \mathrm{~F}) *(44 / 12)$}

In the Eq. (1), $\mathrm{ECO}_{2}$ stand for the emissions of $\mathrm{CO}_{2}$. W represents for the quantities of MSW and DOC represents for biodegradable organic carbon, which can be calculated by the weighted average of the biodegradable organic carbon from different groups of MSW (IPCC recommends that the default value of East Asia countries is $14 \%$ ). DOC $_{F}$ is the proportion of organic carbon in real decomposition with the data of $50 \%$, which is recommended by IPCC. MCF is oxidation factor of the methane. $\mathrm{F}$ is the volume ratio of $\mathrm{CO}_{2}$ in landfill gas and the recommending value of $\mathrm{F}$ is $50 \%$ from IPCC. (44/12) means molecular weight ratio of $\mathrm{CO}_{2} / \mathrm{C}$.

The calculating carbon emission of waste incineration is as following:

$$
\mathrm{ECO}_{2}=\mathrm{W}^{*} \mathrm{CF}^{*} \mathrm{OF}^{*}(44 / 12)
$$

In this Eq. (2), CF is the MSW combustible carbon content and it has more carbon from rubber comparing with DOC. In recent years, the average content of rubber of MSW in our country is $7 \%-12 \%$, and the recommending value from IPCC is $67 \%-75 \%$. Thus, the proportion of carbon in rubber group accounts for $4 \%-9 \%$ of the total weight of the garbage. We take $4 \%$ here, so CF is $18 \%$. $\mathrm{OF}$ is oxidation factor. We take $85 \%$ in consideration of incineration of mixed waste and incineration technology in our country.

The calculating carbon emission of composting is as following:

Eco2 $=\mathrm{W}^{*} \mathrm{DOC}^{*} \mathrm{DOC}_{\mathrm{F}} *(44 / 12)$

In the Eq. (3), after composting completely decomposes, the decomposition rate of DOC is more than $95 \%$. 2/3 of the carbon transforms to $\mathrm{CO}_{2}$ in the process of composting, and the other $1 / 3$ is used for cell synthesis. DOC is 0.65 . 


\section{The results and discussions}

The major data in this paper comes from Shenzhen Statistical Yearbook and Shenzhen Municipal Bureau of Sanitation. The survey data comes from professor Miu from Huazhong University of Science and Technology in October, 2011.

In 2000, there were 2,019,000 tons of waste transportation and disposal in Shenzhen city. To 2011, the total amount of MSW were 4,818,200 tons, with 13,200 tons of daily waste production. There were 4,577,300 tons of innocuous disposal waste, with 1,781,600 tons of burning waste and 1,795,700 tons of sanitary and landfill. The innocuous disposal rate of MSW was $95.0 \%$. The average growth rate of waste was $7.72 \%$ from 2000 to 2011.The carbon emission produced by landfill, incineration and composting between 2001 and 2011 were shown in Table 1.

Table 1 calcualtion carbon emissions

\begin{tabular}{|l|l|l|l|}
\hline Year & Landfill & Incineration & Composting \\
\hline 2000 & 223.82 & 113.32 & 67.47 \\
\hline 2001 & 242.65 & 122.86 & 73.15 \\
\hline 2002 & 244.87 & 123.98 & 73.81 \\
\hline 2003 & 360.1 & 182.33 & 108.55 \\
\hline 2004 & 384.48 & 194.67 & 115.9 \\
\hline 2005 & 368.96 & 186.81 & 111.22 \\
\hline 2006 & 398.88 & 201.96 & 120.24 \\
\hline 2007 & 450.96 & 228.33 & 135.94 \\
\hline 2008 & 488.63 & 247.4 & 147.29 \\
\hline 2009 & 527.41 & 267.04 & 158.98 \\
\hline 2010 & 530.73 & 268.72 & 159.99 \\
\hline
\end{tabular}

From the table above, judging from transverse direction, in the same year and with the same amount of waste disposal, the largest amount of carbon emissions were come from landfill, followed by incinerating waste, and waste composting contributed the least carbon emission. We can see that waste composting produced much less carbon than landfill and incinerating waste. Waste composting should be strongly advocated. Incineration power generation technology produced less carbon emissions than landfill, which should be advocated in the process of waste disposal. In addition, incineration power generation technology should be improved to reduce the carbon emissions per unit of power generation. Vertically, from 2000 to 2010, annual carbon emissions showed a rising trend in the methods of landfill, incinerating or composting. The reasons were that the annual amount of MSW increased dramatically with the development of economy and the improvement of living standard of residents, leading to negative impacts to the city and the environment. Thus, the government and relevant departments should take corresponding measurements to reduce the damage to the city and the environment.

\section{Conclusions}

Low-carbon strategy has become a primary mean to deal with carbon emissions in many countries or local governments. A number of measures have been carried out in some cities, such as collection of classified wet and dry waste, energy recovery from municipal solid waste incineration power generation, anaerobic digestion of kitchen waste for methane production, etc. The carbon emissions created by waste composting treatment were lower than those of waste landfill or incineration. Despite of relatively immature composting technologies in China and the proportion of which utilize composting was lowest among the three methods. There are abundant nitrifying bacteria in composting. Previous research has shown that the rate of compostable N2O emissions would be significantly reduced if matured compost which contained nitrite nitrifying bacteria was added to the composting [6]. During intermission of compost ventilation, the $\mathrm{CH}_{4}$ generated in the compost escape to the surface layer of the compost, and then would encounter methane-oxidizing bacteria and been oxidized. Thus, the amount of carbon emissions would be 
reduced. Due to it has good effect on minimization and reclamation, the technology of municipal solid waste composting would reacquire attention.

The amount of carbon emissions released by landfill were relatively significant, while by carrying a series of measures to recycle landfill gas could decrease carbon emissions effectively. Landfill regeneration experiment in Germany has shown higher shrinking effect, which only carried out general mining process----back filling, dry density of waste increased by 50\%, and after selection and biological treatment, the amplification went up to $85 \%$. Greenhouse gas generated from municipal solid waste in the landfill could be reduced by oxygenation of methane-oxidizing bacteria which lived on the cover layers. The quantity and activity of methane-oxidizing bacteria could be increased by different covering materials and plants grown on the cover layers. In addition, the plants grown on the cover layers could assimilate nitrogen in order to restrain the methane emissions. Currently, more than 500 landfills in over 20 countries recycle landfill gas, and its major utilization modes were burning directly to generate steam for domestic and industrial heat supply, utilizing internal-combustion engine for grid connected generation, using as power fuel for means of transportation, using as pipeline gas after dehydration and purification treatment, being used to manufacture methanol. Electricity generation, domestic fuel and automobile fuel were three of the most popular utilization methods.

Waste incineration power generation was a quick and thorough way, which could convert waste into heating energy. It could not only reduce carbon emissions, but also realized resources recycling. By investigating into the process of waste incineration power generation in Athens, capital of Greece, it could be found that its emission reduction of greenhouse gas has exceeded carbon-containing emissions of waste, which meant that the process of waste incineration power generation was greenhouse gas sink [7]. Japan, Italy and other countries have established hundreds of incineration power plants of municipal waste, the handling capacity of municipal solid waste incineration in Japan could reach 75\% currently. On the premise of advanced processing technology, implementation of equipment and instrument as well as tight operational management, waste incineration power generation could operate steadily and discharge with standard level. Accordingly, the pollution for the atmosphere would be reduced effectively.

\section{Acknowledgements}

This work was financially supported by the National Natural Sciences Foundation of China (71273022,71420107025), Beijing philosophy and social sciences Foundation (12JGB061) and Beijing education scientific Foundation(AAA12007).

\section{References}

[1] Lei Zhao, Dezhen Chen, Guangyu Liu: China Environmental Science Vol.30 (2008), p.1634-1641. In Chinese

[2] Elhanandeh A, Elzein A: Waste Management Vol. 29 (2009), p. 2188-2194.

[3] Calabro P S: Waste Management Vol. 29 (2009), p.2178-2187.

[4] Mohareb A K, Warith M A, Diaz R: Resource Conservation and Recycle Vol. 52 (2008), p.1241-1251.

[5] Yifeng Chen, Ge Pu, Yingyu Ran: Journal of Chongqing Institute of Technology Vol. 21(2007), p.25-28. In Chinese

[6] Fukumoto Y, Suzuki K, Osada T: Environmental Science \& Technology Vol. 40 (2006), p. 6787-6791.

[7] Papageorgiou A, Karagiannidis A, Barton J R: Waste Management and Research Vol.27 (2009), p.928-937. 